\title{
UM ARGUMENTO OCKHAMIANO CONTRA O REALISMO SOBRE A CATEGORIA DA QUANTIDADE
}

Ernesto Perini Santos

SINTESE - Guilherme de Ockham caracterizouse por uma rigorosa análise da linguagem. Ao criticar o realismo, mostrou ser necessário distinguir o que pertence à ordem lingüistica e o que a ela năo pertence, e com isto procurou mostrar que só existem seres singulares e, por isso, o universal só existe na linguagem. Distinguindo entre os traços lingüísticos e os reais em torno da noção de unidade, ele mostra que a quantidade discreta numérica não possui existência real, pois entre as categorias só a substância e a qualidade são reais, sendo que as demais a elas se referem.
ABSTRACT- William of Occam is characterized by a rigorous analysis of the language. Criticising the realism, he has shown that it is necessary to distinguish what belongs and what not belongs to the linguistic order. Thus he tried to show that there are only singular beings, and therefore the universal exists only in the language. By the distinction between the linguistic characteristics and the real characteristics in the notion of unity, he shows that the numerical distinct quantity doesn't have a real existence, since among the categories only the substance and the quality are real, while the rest is referred to them.

Os argumentos de Ockham contra posições realistas têm como centro mostrar a distinção entre o que pertence à ordem linguística e o que não pertence à ordem linguística; Boler (1985) diz que a intuição central de Ockham é que o que é relativo à mente é dependente da mente, outra forma de dizer que o modo como a mente organiza a experiência não pode ser pensado senão como uma organização da experiência pela mente, não como um traço do real independente da mente. Estes dois pontos são formas convergentes de descrever aspectos fundamentais da filosofia ockhamista e, sobretudo, de seu nominalismo. A tese central do nominalismo, que só existem singulares e que todo universal só existe na linguagem, é o ponto crucial desta separação de ordens. Os argumentos ockhamianos serão estratégias de mostrar a separação entre estas duas ordens de consideração, entre a

Departamento de Filosofia, UFMG.

\begin{tabular}{|l|l|l|l|l|l|}
\hline VERITAS & Porto Alegre & v. 42 & $\mathrm{n}^{2} 3$ & Setembro 1997 & p. 647-658 \\
\hline
\end{tabular}


ordem lingüística e a ordem não lingüística e, no que diz respeito à questão dos universais, entre um dominio no qual só existem singulares e não universais, e um domínio no qual existem universais. Como observa mais uma vez Boler, a ferramenta central de Ockham aí não é sua navalha, seu principal instrumento para cortar universais é justamente esta separação de ordens, que ele chama de cutelo de Ockham, Ockham's cleaver.

Neste artigo vou examinar um argumento ockhamiano que procura esclarecer justamente a distinguir uma análise de traços lingüísticos e uma análise de traços do real, em torno noção de unidade. Inicialmente vou desenvolver 0 argumento ockhamiano que aparece no capítulo 15 da Summa logicae - e para isto será necessário partir do capitulo 14; o exame deste argumento nos levará à análise da quantidade discreta numérica. Procuro mostrar um possivel desenvolvimento ockhamiano e um modo de interpretar seus resultados dentro da crítica mais ampla ao realismo.

\section{II}

O capitulo 14 da SL de Ockham inicia o tratamento propriedades especíicas de termos - não basta ao lógico um conhecimento geral sobre termos, sobre a divisão entre termos mentais, escritos e falados, entre categoremáticos e sincategoremáticos, entre concretos e abstratos, e outras propriedades que tanto preocuparam lógicos terministas; o lógico deve estudar também outras características dos termos. O Venerabilis Inceptor inicia esta nova investigação pelo exame de termos de segunda intenção, termos que falam sobre termos, tal como pensa Ockham, ponto que será um terreno privilegiado de oposição entre nominalismo e realismo, da separação justamente entre as duas ordens de consideração. Os primeiros termos tratados são os opostos 'universal' e 'singular'.

O filósofo inglês começa sua análise pelo termo 'singular'. Compreende-se 'singular' de dois modos:

(i) num sentido 'singular' significa tudo que é um e não muitas coisas (omne illud quod est unum et non plura) [singular1]; o universal como qualidade da alma predicável de muitos é singular neste sentido, é uma qualidade da alma;'

(ii) num outro sentido o que é um e não muitos [singular1] e não é destinado a ser signo de muitas coisas (nec est natum esse signum plurium) [singular2]; neste sentido nenhum universal é singular. ${ }^{2}$

Se o universal é o que não é numericamente um - o que muitos dizem do universal, acrescenta Ockham - nada é universal (Unde vocando universale aliquid

\footnotetext{
"Est autem primum sciendum quod 'singulare' dupliciter accipitur. Uno modo hoc nomen 'singulare' significat omne illud quod est unum et non plura. Et isto modo tenentes est quod universale est quaedam qualitas mentis predicabilis de pluribus, nom tamen pro se sed pro illis pluribus, dicere habent quod quolibet universal est vere et realiter singulare (...)" (SL, XIV, 13-18; p. 50).

- "Aliter accipitur hoc nomen 'singulare' pro omni quod est unum et non plura, nec est natum esse signum plurium. Et sic accipiendo 'singulare' nullum universale est singulare [...]" (SL, 14, 23-25; p. 50).
} 
quod non est unum numero [...] dico quod nihil est universale), a não ser que se abuse deste termo, chamando um povo de universal, por exemplo (veremos como exemplos como este não trazem problemas para Ockham). Tudo o que existe é singular1; não há nada que seja oposto a singular1, não há algo como um universal1. O universal é assim universal apenas por significação, sendo ele mesmo uma coisa singular.

Deve-se dizer que qualquer universal é uma coisa singular, e por isso näo é universal senão por significação, porque é signo de muitas coisas. "Dicendum est igitur quod quolibet universale est una res singularis, et ideo non est universale nisi per significationem, quia est signum plurium" (SL, 14, 31-33; p.50). ${ }^{3}$

Este enunciado claro de Ockham fecha o quadro de relações entre universal e singular, que podemos apresentar do seguinte modo:

\begin{tabular}{|l|l|}
\hline $\begin{array}{l}\text { singular1: tudo o que é um e não } \\
\text { muitas coisas }\end{array}$ & $\begin{array}{l}\text { singular2: singular1 e não é destinado } \\
\text { a ser signo de muitas coisas }\end{array}$ \\
\hline & $\begin{array}{l}\text { universal2: singular1 e é destinado } \\
\text { a ser signo de muitas coisas. }\end{array}$ \\
\hline
\end{tabular}

Tudo o que existe é singular1, i.é. é uma coisa singular; das coisas que existem, algumas coisas não são signo senão de uma só coisa - singular 2 - e outras, de muitas - universal2. Esta divisão não é exaustiva, existem coisas que não são signos de nada, não sendo portanto nem singular2 nem universal2. Observe-se que não há nada no quadrado inferior esquerdo, não há um universal1, ou seja, não há nada que seja oposto a singular1. Uma outra leitura desta passagem diria que também coisas que não são signos podem ser singular2 já que, não sendo signos, não podem ser signo de muitos. Esta última leitura está mais presa ao que diz explicitamente Ockham. Minha hipótese é contudo que a distinção entre singular2 e universal2 é uma distinção lingüística, só incluindo portanto, para Ockham, signos. Embora meu argumento trabalhe com esta hipótese, não a justificarei aqui, tratarei mais extensivamente apenas de universais; acredito que a hipótese geral acerca da passagem ficará clara com o desenrolar do argumento. Seja como for, o argumento apresentado a respeito de universais é independente deste ponto sobre a definição de singular2.

No restante do capitulo, Ockham recorre a Avicena para confirmar que o universal é uma forma única no intelecto, relacionada com muitas coisas, à metáfora do Sol, uma coisa única que se relaciona com muitas coisas, e distingue entre universal natural - termo da linguagem mental - e universal por convenção termo de alguma linguagem convencional. Estes desenvolvimentos complementares não interessam contudo a nosso argumento.

3 Todas as citações referem-se à parte I da Summa logicae; a numeração indica, respectivamente, o capítulo, as linhas e a página da edição utilizada. 
O capítulo 15 vai provar o que foi dito, i.e. que o universal não é uma coisa fora da alma. Deve-se perceber que esta é parte da tese principal do capítulo 14: tudo o que existe é uma coisa singular, não existe nada que seja uma coisa universal, o universal é uma coisa singular signo de muitas coisas. Pode-se provar de maneira evidente (evidenter) que nenhum universal é uma substância existente fora da alma, promete o filósofo inglês.

Inicialmente, nenhum universal é uma substância singular e uma em número (nullum universale est substantia singularis et una numero). Esta tese parece em contradição a uma conseqüência do capítulo anterior, que diz que todo universal é uma coisa singular, se associarmos 'res singularis' a 'substantia singularis', o que pode ser feito em Ockham. O Venerabilis Inceptor trata contudo aqui do universal na medida em que é universal, i.e. na medida em que é signo de muitos. Reunindo estas duas sentenças sobre o universal, podemos dizer o universal, na medida em que é uma intenção da alma, é uma coisa singular, um singular1, mas considerado apenas desta forma, ele não é universal; como intenção da alma, ele não é diferente, por exemplo, de um termo singular2, digamos 'Sócrates', ou mesmo de algo que não seja um termo, como o homem Sócrates. Se isto é assim, não definimos 'universal' ao dizer que é uma coisa singular - aliás, nada é definido desta forma pois não dizemos em que ele é diferente de outras coisas que não são universais, signos ou não signos.

Vamos definir universal como uma coisa singular que é signo de muitas coisas, trata-se assim de um singular1 universal2, retomando o nosso quadro de opostos. Assim, nenhum universal, na medida em que é universal, i.é. na medida em que lhe atribuimos a caracteristica específica que o define como universal, é singular; entendendo assim, podemos dizer que nenhum universal é uma substância singular e uma em número, a primeira tese que se quer provar no capitulo 15. Admitindo-se que todo universal é substância singular e uma em número, Sócrates poderia ser universal, já que não há mais razão para que uma substância singular seja universal e não outra. A tese refutada pode ser descrita como uma confusão: universal não é singular2 - o que é trivial, mas é singular1; o que também é trivial; ambas caracterizações fazem parte de sua definição. Mas, ao se dizer que o universal é singular1, não fazemos referência à sua capacidade de significar outra coisa, o universal é singular1 se fizermos abstração de sua qualidade de signo. Se não considerarmos a qualidade de signo, então o universal, aqui a intenção da alma, é exatamente igual a Sócrates, um coisa singular - a conseqüência absurda que Ockham extrai da tese a ser refutada. ${ }^{4}$

Deve-se observar aqui que Ockham não diz que 'Sócrates' seria universal, mas Sócrates, estamos num domínio onde não se pode distinguir signos de não signos. Assim, dizer que um termo singular é simplesmente uma coisa singular é incorrer no mesmo erro que dizer que o universal é uma coisa singular, embora talvez com conseqüências menos nefastas para Ockham neste contexto. Não ha-

\footnotetext{
A consequência da posição realista que Sócrates seria um universal tem uma outra versão na Ordinatio, apresentada por Adams, p.31-31; são dois argumentos diferentes.
} 
veria mais razão para dizer que 'Sócrates' é um termo singular do que Sócrates; ele chama atenção para esta distinção em Quodlibet V, q. 12, denominando 'termo discreto' o termo que significa um só indivíduo. ${ }^{5}$

Depois de ter mostrado a conseqüência absurda que se pode extrair da tese oposta, Ockham vai provar sua tese:

Nenhuma substância singular é assim universal, mas toda substância é uma em número e singular... "Nulla igitur substantia singularis est aliquod universale, sed omnis substantia est una numero et singulanis..." (SL, 15, 9-11; p. 51).

Começa então a prova ockhamiana. Toda substância é ou bem uma coisa e não muitas, ou muitas coisas:

(a) se é uma coisa e não muitas, é uma em número - é isto o que todos entendem por 'numericamente um' "unum numero", q.e.d.;

mas se é muitas coisas "si autem substantia est plures res", é muitas coisas singulares ou muitas coisas universais;

(b) na primeira hipótese, uma substância seria muitas coisas singulares; o universal, ainda que distinto de um particular tomado individualmente "distingueretur a particulari uno", não seria distinto dos singulares "a particularibus"; se o universal for muitas coisas singulares, uma solução mereológica, não há nenhuma substância que não seja substância singular (chamar um todo composto de particulares de universal, embora seja um abuso de linguagem, não traz poblemas para Ockham, pois só existem neste caso coisas singulares), q.e.d.;

(c) na segunda hipótese, o universal seria muitas coisas universais; que se tome uma coisa universal desta coleção; as perguntas acima se repetiriam in infinitum, ou então estabelece-se que nenhuma substância é universal se não for ao mesmo tempo singular, i.é. se paramos a progressão do argumento dizendo que alguma coisa universal é singular, o que é absurdo; logo, nenhuma substância é universal.

Podemos reconstruir o argumento ligando-o às definições do capítulo anterior.

Tese 1: não há nada que não seja singular1 (tudo o que é é uma coisa singular);

Tese 2: nenhum universal é uma coisa existente fora da alma.

Argumento: seja uma substância $x$; ela é uma coisa ou é muitas coisas;

a) se $x$ é uma coisa singular, tem-se o que se quer demonstrar;

b) se $x$ é muitas substâncias, ou é muitas coisas singulares, ou muitas coisas universais;

c) se é muitas coisas singulares, não é nada além das coisas singulares, tem-se portanto o que se quer demonstrar;

d) se é muitas coisas universais, repete-se a questão;

e) se se obtém a mesma resposta que (c), tem-se o que se quer demonstrar;

"Nunc autem logice loquendo, tripliciter accipitur 'singulare' et 'individuum': uno modo dicitur singulare illud quod est una res numero et non plures; alio modo dicitur singulare res extra animam, quae est una et non plures, nec est signum alicuius; tertio modo dicitur singulare signum proprium uni, quod vocatur terminus discretus" (Quodlibet, V, 12, 14-19; p.529). 
f) se não se obtém (c), (f') ou se entra numa progressão in infitum, (f') ou se diz que alguma coisa universal - pela hipótese examinada - é ao mesmo tempo singular - pela tese 1 - (vel stabitur quod nulla substantia est universalis ita quod non singularis), o que é contraditónio.

O ponto sensivel deste argumento é (f'): a resposta realista consistiria aqui justamente em dizer que năo é necessário uma contradição, pode-se dizer que uma substância universal é uma coisa, e não muitas, e não singular. Ora, Ockham não examina esta hipótese aqui, o argumento então simplesmente repousa sobre a pressuposição que toma por verdadeiro justamente o que está em jogo, a saber que não existem coisas universais.

Qual é exatamente a hipótese realista que poderia contrapor-se a Ockham aqui? O capítulo pretende provar que nenhum universal é uma coisa existente fora da alma; este primeiro argumento diz que nenhum universal é uma coisa numericamente uma. Para que este argumento funcione dentro deste capítulo, ele tem dois momentos:

(i) não existe nada fora da alma que não seja singular;

(ii) nenhum universal é singular, logo

(iii) nenhum universal é uma coisa existente fora da alma.

A resposta realista pode atacar a premissa (i) ou (ii); o argumento concentrase no estabelecimento de (ii); vamos supor aqui que (i) seja aceito pelos realistas, o que de resto parece ser verdadeiro para os realismos que Ockham tem em vista, tanto o de Scotus quanto versões do realismo moderado como a de Burleigh [cf. Adams, 13-69].

O realista deve então dizer que o universal é singular de algum modo. A tese ockhamiana pode então ser reformulada da seguinte maneira:

(i') näo existe nada fora da alma que não seja numericamente um;

(ii') nenhum universal é numericamente um, logo

(iii') nenhum universal é uma coisa existente fora da alma.

Colocado desta forma, a oposição realista muda de figura; ela não vai exatamente recusar (ii'), mas dizer que existe uma unidade que não é numérica. 0 argumento realista que poderia se contrapor aqui seria o seguinte:

(a) não existe nada fora da alma que não seja um;

(b) nem toda unidade é numérica;

(c) o universal tem uma unidade não numérica, logo

(d) o universal pode existir fora da alma, tendo uma unidade não numérica.

Esta estratégia de resposta pode portanto aceitar (ii') e (i'); deverá ser estabelecido então que nem toda unidade é numérica. Voltando à recusa de (f"), o que o realista dirá será que não é necessário uma contradição, porque o universal é uma coisa e não muitas, 'uma coisa' sendo entendido como designando uma unidade não numérica, unidade não incompativel com sua universalidade.

$\mathrm{O}$ que o argumento de Ockham deixa de examinar aqui é portanto (b), hipótese que permitiria que se bloqueasse seu argumento.

Uma possível saída ver outros argumentos anti-realistas que vão atacar este ponto. Outra possibilidade é ver a teoria da unidade ockhamiana, que não permite (b). Vamos tentar esta segunda via. 
O primeiro ponto a ser esclarecido é o que o realista precisa para contrapor-se à tese ockhamiana. É preciso que desginar algo como tendo uma unidade não numérica desgine uma coisa existente fora da alma, i.é. a distinção entre unidades não numéricas é uma distinção entre coisas. Este ponto pode ser esclarecido pelo exame da hipótese contrária, da unidade não numérica não se referir a uma distinção entre coisas. Seja por exemplo a distinção entre um homem e uma mosca. Se digo que $x$ é um homem e que $y$ é uma mosca, estou dizendo que são duas coisas diferentes. Não posso explicar a distinção entre aquilo a que se refere 'homem' e aquilo a que se refere 'mosca' senão dizendo que são duas coisas distintas - $x$ e $y$ são necessariamente coisas distintas, se estas sentenças são verdadeiras. Se digo contudo que $x$ está em Belo Horizonte e que y está em Porto Alegre, não é preciso supor que se trata de duas coisas distintas. É claro que pode se tratar de duas coisas distintas, mas isto não é necessário para explicar a điferença entre as duas sentenças - uma mesma coisa pode estar agora em Belo Horizonte e depois em Porto Alegre; dizer que uma mesma não pode estar ao mesmo tempo em dois lugares não altera em nada nosso ponto, pois estaria trabalhando com um predicado mais complexo, 'estar num lugar I num tempo t'; o problema aqui é o da individuação de eventos, não de coisas. A distinção estabelecida por sentenças que falam de lugares não é uma distinção entre coisas, posso dizer de uma mesma coisa que ela esteve em lugares diferentes. Não existe então uma distinção real, i.é. entre coisas, que corresponda à distinção de lugares.

Pois bem, ao realista não basta dizer que a unidade não numérica opera uma distinção não real, é preciso que haja uma distinção entre as coisas. A unidade não numérica deve funcionar como 'homem' e 'mosca', não como 'em Belo Horizonte' e 'em Porto Alegre'. Com efeito, para dizer que o universal é uma coisa existente fora da alma por ter uma unidade não numérica é preciso que 'unidade numérica' designe uma distinção entre as coisas. Um exemplo tornará este ponto mais claro. Digamos que o termo universal 'homem' tenha uma unidade não numérica (o que é defendido pelo realista). A tese realista dirá que existe uma coisa designada pelo termo universal 'homem' diferente de outras coisas, diferente, por exemplo, de cada homem particular. Assim poderei dizer que existe uma coisa fora da alma que corresponde ao universal 'homem'.

A hipótese contrária não resolve o problema do realista. Com efeito, se disser que 'unidade não numérica' funciona com 'em Belo Horizonte', não é preciso que haja uma coisa fora da alma que corresponda a uma unidade não numérica. Assim como posso dizer 'Tostão esteve em Belo Horizonte' e 'Tostão esteve em Porto Alegre' sem que seja necessário que haja dois Tostões, poderia dizer que o universal 'homem' tem uma unidade não numérica diferente dos homens singulares, mas que isto não implica que haja uma coisa que corresponda ao universal 'homem' diferente dos homens singulares. É claro que isto não resolve o problema do realista, pois não haverá nesta hipótese coisa alguma fora da alma a que corresponda o universal 'homem', justamente a tese que se quer defender. Ockham admite ele mesmo uma unidade não numérica, a unidade da espécie e do gênero é 
unitas minor unitate numerali [SL, 39, 62; p.116], o que não traz problema nenhum se ela não corresponder a uma distinção real.

$\mathrm{O}$ argumento realista então deve ser reconstruído:

(a') não existe nada forma da alma que não seja um;

(b') nem toda unidade é numérica;

(c') o universal tem uma unidade não numérica;

(d') a unidade não numérica corresponde a uma distinção real, logo

(e') o universal pode existir como uma coisa fora da alma, tendo uma unidade não numérica.

Neste caso a premissa fundamental do realista é (d'). Esta premissa é atacada pela teoria ockhamiana da quantidade.

\section{V}

A tese geral ockhamiana acerca das categorias é que as únicas categorias que designam coisas reais distintas são a substância e a qualidade; todas as outras categorias designam substâncias e qualidades. O estatuto da categoria da quantidade é um dos pontos sensiveis na articulação entre linguagem e real para os nominalistas; a questão é complexa e será abordada aqui apenas na medida em que está diretamente ligada ao argumento que nos interessa (cf. Biard, 1991). Termos pertencentes à categoria da quantidade não desginam senão substâncias e qualidades, i.é. coisas designadas por substâncias ou qualidades. Esta tese é expressa no inicio do exame desta categoria na Expositio in Librum Praedicamentorum Aristotelis.:

[...] não é a intençåo de Aristotéles que a quantidade seja uma categoria remetendo a uma coisa absoluta, real e totalmente distinta das coisas no gênero da substância e no gênero da qualidade, - como se defende comumente -, mas sua intenção é que a nada se remeta pelo gênero da quantidade que não seja realmente substância ou qualidade. "[...] [non est intentio Aristotelis quod quantitas sit quoddam praedicamentum importans rem absolutam, realiter et totaliter distinctam a rebus in genere substantiae et in genere qualitatis, - sic communiter tenetur -, sed est intentio sua quod nulla res importatur per genus quantitatis quin sit realiter substantia aliqua vel qualitas" (Expositio, X, 4, 16-21; p.205).

A quantidade que nos interessa aqui é a quantidade discreta numérica. Não vamos entrar na apresentação ockhamiana da quantidade, basta-nos ver como Ockham recusa que a quantidade discreta numérica corresponda a uma distinção real, que remeta a coisas realmente distintas.

Vejamos como este ponto é estabelecido. $\mathrm{O}$ argumento ockhamiano gira sobretudo em torno da noção de substância, como observa Biard; toda qualidade remete à substância ou à qualidade, $\mathrm{e}$

[...] é finalmente à substância, como sujeito de qualidades, que a quantidade é reconduzida [...] (Biard, 1991, p.96).

Veremos esta estratégia ockhamiana à obra aqui. Trata-se de provar que a quantidade discreta numérica não é uma substância absoluta. Se o número fosse um acidente por si uno [per se unum], i.é. um acidente realmente existente em um sujeito real, deveria ter um sujeito por si uno. Seja a trindade de três cães. Ou a 
trindade está toda subjective em qualquer parte dos três cães, ou cada parte da trindade está em uma parte dos três cães. A primeira hipótese não pode ocorrer, pois o número estaria ao mesmo tempo em diversos sujeitos (este cão seria três cães etc.), da mesma forma que cada parte do fogo é fogo. Ockham aponta aqui para distinção entre mass terms e termos com referência distribuida; é claro que só os segundos tem unidade numérica, já que o próprio dos primeiros é justamente não poder ser contado, não ter portanto unidade numérica. A segunda hipótese não pode ocorrer tampouco, pois os sujeitos de tais partes não seriam por si unos, logo o número não seria uma coisa por si una; como os sujeitos do número estaniam separados, não poderiam ser um sujeito de um mesmo acidente, logo não haveria um mesmo acidente, aqui, de número, comum aos três sujeitos (não seriam três cães, mas um cão separado do outro); ${ }^{6}$ não posso portanto identificar o que seria uma coisa real correspondendo à trindade distinta dos três cães.

Vamos ver como este argumento funciona para o nosso caso, a unidade não numérica; ou a unidade não numérica está toda em qualquer parte, ou não. $\mathrm{O}$ primeiro caso não pode ocorrer, pois neste caso este cão teria a unidade inteira de um gênero, este outro cão também, e assim por diante, o que é impossivel. O problema aqui não é a possibilidade de haver uma espécie ou um gênero de um só indivíduo, mas que cada indivíduo teria a unidade genérica toda. Se alguém perguntasse o que é a unidade genérica dos cães, eu poderia apontar para um cão, o que é absurdo. Deveria ser capaz de dizer aqui, por exemplo, que um time de futebol é uma coisa una, diferente dos jogadores individuais, cuja unidade está em cada uma das partes; poderia então dizer que este jogador é um time, e que este outro também, e assim por diante.

A segunda hipótese é a da unidade não numérica estar em suas diferentes partes dividida sob diferentes razões, i.é. cada parte da unidade não numérica não poderia ser chamada unidade não numérica. $O$ problema aqui seria paralelo ao problema da trindade. Os sujeitos de tais partes da unidade numérica não seriam por si unos, logo o número não seria uma coisa por si una; como os sujeitos do número estariam separados, não poderiam ser sujeitos de um mesmo acidente, logo não haveria um mesmo acidente, aqui, de número, comum aos diferentes sujeitos da unidade não numérica, não haveria assim uma coisa que pudesse ter uma unidade não numérica existinđo realmente (não haveria como identificar uma coisa que fosse uma existindo em três cães separados, não haveria portanto uma coisa como a unidade não numérica).

Se o primeiro problema para o realista era que um só cão teria a unidade não numérica do gênero, o problema aqui é identificar esta unidade como uma coisa, com sua unidade feita de várias outras coisas diferentes que são elas mesmas unidades. Esta unidade seria feita então de coisas unas diferentes entre si, seria

\footnotetext{
- "Item, de quantitate discreta probo quod non sit talis res, et primo de numero: quia si sit accidens per se unum, oportet quod habeat subiectum per se unum. Sed nullum tale potest dari; quia accipio trinitatem trium canum: aut talis trinitas est subiective in quolibet illorum trium canum: aut una pars est in uno, et alia in alio. Primum non potest dari, quia tunc idem accidens numero esset simul in diversis subiectis. Si autem detur secundum, ergo sicut suiecta istarum partium non faciunt per se unum, ita nec accidentia exsistentia in eis pacient per se unum: igitur numerus non erit aliquod ens per se unum" (Expositio, X, 4, 179-188; p.212).
} 
uma pluralidade de coisas diferentes. É claro então que o sentido no qual eu digo que um cão é uma só coisa não é o mesmo que eu digo que os cães são uma só coisa; minha segunda sentença deve identificar uma coisa única comum a diferentes coisas que compõe esta unidade genérica, não numérica; mas aí já há uma pluralidade de coisas diferentes identificadas pela unidade numérica, a unidade que identifica diferenças entre coisas é portanto a unidade numérica, e não tenho outro critério para identificar alguma coisa.

Se a uma coisa identificada por uma unidade não numérica acrescento outra coisa, passo a ter duas coisas; se à unidade não numérica de dois cães, supondo que haja alguma coisa identificado por esta unidade de dois cães, acrescento outro cão (os dois primeiros se reproduziram), passo a ter duas coisas. A objeção de Ockham pode ser vista então num nivel mais abstrato: se tenho uma coisa e a ela acrescento outra coisa, passo a ter duas coisas, e não uma.

De certa forma, uma realista pode responder dizendo que o que está em jogo é justamente a possibilidade de uma unidade não numérica identificar uma coisa, o argumento supondo como premissa então precisamente o que está em jogo. É isto o que dizem, por exemplo, Adams (cf., por exemplo, p. 35, 59, 65) e Michon (p. 395-396). Burleigh, por exemplo, distingue dois sentidos de unidade numérica, um mais amplo, tudo o que é contável, e outro relativo à substância singular (cf. Michon, 396n); esta possibilidade não é contemplada por Ockham. Não há muito como levar adiante uma resposta ockhamiana, ficamos com duas teorias que não se encontram. Michon diz assim que Ockham monta uma verdadeira máquina de guerra anti-realista;

Mas esta condenação violenta poderia ter como resposta que ela produz apenas o que ela aceitou nas suas premissas, em resumo, ela poderia ser denunciada como circular (Michon, 426).

\section{VI}

O que o realista defende, contra Ockham, é que podemos identificar coisas diferentes com distinções entre diferentes tipos de unidade. A unidade numérica distingue indivíduos singulares, a unidade não numérica também distingue coisas realmente existentes, distinções que se sobrepõem; aqui não há muito como parar a multiplicação de coisas distinguidas correspondendo a diferentes tipos de unidade (a unidade das raças de cães, da espécie cão, de mamifero, de animal etc.), uma critica de Aristóteles a Platão (Met., A, 9, 990b1-7), mas isto talvez não seja um problema para o realista. As distinções na categoria da quantidade correspondem a divisões entre coisas, e o Venerabilis Inceptor, neste argumento, não mostrou que isto é impossivel, mas antes trabalhou com esta suposição.

É verdade que o Venerabilis Inceptor não ataca diretamente esta premissa, não diz porque não podemos ter diferentes tipos de unidade identificando coisas, quer unidade numérica e não numérica, quer diferentes sentidos de unidade numérica, e é dificil ver uma saída nominalista aqui. A resposta ockhamiana aqui contudo estará não no desenvolvimento de paradoxos relativos à unidade, que parecem sempre levar a. uma petição de princípio, mas na teoria geral da quantidade. 
O que o realista deve ser capaz de defender é que a categoria da quantidade opera divisões reais entre as coisas. Deve ser capaz de dizer que identificamos coisas diferentes quando aplicamos diferentes termos relativos à quantidade discreta numérica. A tese realista não pode se restringir à unidade, mas deve mostrar como tratar em geral a categoria na qual está a unidade, deve mostrar que as divisões da quantidade correspondem a divisões do real, não relativas à mente. Os paradoxos relativos à trindade são então tão relevantes para o nosso ponto quanto os paradoxos da unidade. A outra hipótese seria dizer que a unidade não pertence à categoria da quantidade, que a diferença entre falar que há uma coisa e falar que há três coisas, é da mesma ordem que a diferença entre falar que ' $x$ é uma mosca' $e$ ' $x$ está em Porto Alegre'.

Deve-se observar, é verdade, que em um texto da Summa é dito que a unidade, de certa forma, não é um número - não é uma quantidade discreta pois não tem partes que se encontram num limite comum, o que define a quantidade discreta (SL, 44, 175-178; p.145). Esta hipótese ockhamiana não resolve contudo o problema do realista, ela vem justamente negar que a unidade seja algo distinto daquilo que é um, i.é. distinto da substância una e da qualidade una, e não altera sua tese geral que quantidade nunca corresponde a divisões no real (não há espaço aqui para examinar este argumento).

$O$ realista deve dizer aqui que a categoria da quantidade às vezes trata de distinções entre coisas reais, às vezes não. Ou então deve ser capaz de dizer que os paradoxos relativos à trindade dos três cães repousam sobre uma premissa não examinada, da mesma forma que os paradoxos relativos à unidade não numérica.

\section{VII}

A posição realista não está muito confortável ao final deste pequeno percurso ockhamiano. Se é possivel ver que um aspecto de um paradoxo aduzido por Ockham contra o realismo é passivel de uma petição de principio, a refutação funciona em um nivel mais geral como uma teoria acerca de quantidades. Contra o que dizem Adams e Michon, não é verdade que o realista possa escapar das objeções de Ockham apenas com uma petitio principii, ele deve oferecer uma teoria alternativa acerca da quantidade que acomode, por um lado, distinções entre coisas reais dentro da categoria da quantidade e, por outro, responda aos paradoxos ockhamianos relativos à quantidade discreta numérica em geral, não apenas relativos à unidade. Deve mostrar que a tese geral de Ockham sobre a separação entre o que pertence à ordem da linguagem e o que não pertence à ordem da linguagem está errada. A refutação do reałismo não depende de uma premissa não examinada, mas da plausibilidade geral da teoria ockhamiana sobre as relações entre o real e a linguagem; o que Ockham mostra então, mais do que paradoxos localizados, é a dificuldade mais ampla do realismo de separar estas duas ordens, paradoxos localizados podem ser eventualmente incompletos, mas fazem parte de uma crítica geral ao realismo; eles podem não levar a contradições, mas a soluções complicadas para o realista (por exemplo, que a categoria da quantidade por vezes signifique distinções reais, por vezes não). 
Deve-se atentar também para a dificuldade de uma possível saída pela noção de paradigmas incomensuráveis, que impediria qualquer diálogo entre nominalistas e realistas - as premissas diferentes entre um e outro, que vimos no paradoxo examinado, sendo um resultado desta incomensurabilidade. Serei breve sobre este ponto. Por um lado, aqueles que defendem esta posição devem estar preparados para defender, com T. Kuhn, a impossibilidade de uma escolha racional entre teorias; não sei se este é sempre o caso. Este me parece ser de qualquer modo um preço a se pagar quando se recorre à noção de paradigma, o de dizer, por exemplo, que o máximo que podemos ter como teoria geral do conhecimento é uma sociologia do conhecimento ou, em todo caso, uma teoria que não recorre a critérios racionais para mudanças teóricas. Por outro lado, aquele que defende tal posição deveria mostrar que Ockham fala de um mundo diferente do realista, que teses de um e de outro não tratam de pontos comuns, em resumo, que não há como compreender a tese de um do ponto de vista da tese do outro. Parece-me também que esta posição envolve sérias dificuldades, embora não possa aqui argumentar contra ela aqui.

Acredito assim que a crítica ockhamiana ao realismo que gira em torno da noção de unidade é defensável e, mais do que defensável, poderosa. $\mathrm{O}$ debate entre nominalismo e realismo desenvolve-se em torno da relação entre linguagem e real e não pode ser decidido a partir de paradoxos isolados, ou antes estes paradoxos só têm sentido dentro do quadro mais geral da critica nominalista ao realismo.

\section{Referências bibliográficas}

ADAMS, Marilyn McCord. [1987] William Ockham. Notre Dame: University of Notre Dame Press. Vol. I. BIARD, Joël. [1991] Sémiologie et Théorie des Catégories chez Albert de Saxe. BIARD, Joël (ed.). Itinéraires d'Albert de Saxe; Paris-Vienne au XIV Siècle. Paris: Vrin. p.87-100.

BOLER, John. [1985] Ockham's Cleaver. Franciscan Studies (45). p.119-144.

MICHON, Cyrille. [1994] Nominalisme; La Théorie de la Signification d’Occam. Paris: Vrin.

OCKHAM, Guillemi de. [1978] Expositio in Librum Praedicamentorum Aristotelis. Ed. G. GÁL. Opera

Philosophica II. St. Bonaventure: St. Bonaventure University. (Expositio)

OCKHAM, Guillemi de. [1980] Quodlibeta Septem. Ed. J. C. WEY. Opera Theologica IX. (Quodlibet)

OCKHAM, Guillaume d'. [1993] Somme de Logique. Première partie. Ed. Bil. Trad. J. BIARD. Mauvezin: Trans-Europ-Repress. 2 édition revue et corrigée. (SL) 